\title{
Dynamic computed tomography perfusion imaging for detection of cardiac allograft rejection and myocardial ischemia in a heart transplant recipient
}

\author{
Anna Oleksiak ${ }^{*}$, Małgorzata Sobieszczańska-Małek2* , Mariusz Kruk³ , Tomasz Zieliński², Krzysztof Komuda², \\ Cezary Kępka ${ }^{3}$
}

1Department of Intensive Cardiac Therapy, National Institute of Cardiology, Warszawa, Poland 2Department of Heart Failure and Transplantology, National Institute of Cardiology, Warszawa, Poland ${ }^{3}$ Department of Coronary and Structural Heart Diseases, National Institute of Cardiology, Warszawa, Poland *Both authors equally contributed to the study

Correspondence to: Anna Oleksiak, MD, PhD Department of Intensive Cardiac Therapy,

National Institute of Cardiology, Alpejska 42, 04-628 Warszawa, Poland,

phone: +482234343 14, e-mail: aoleksiak@ikard.pl Copyright by the Author(s), 2022 DOI: 10.33963/KP.a2021.0168 Received: November 6, 2021 Accepted: December 2, 2021 Early publication date: December 2, 2021
Cardiac allograft rejection (CAR) is one of the most common complications and the main determinant of morbidity and mortality in the first year after orthotopic heart transplantation (OHT) [1]. Therefore, an accurate and fast diagnosis of CAR is crucial for early treatment, especially since effective immunosuppressive therapies are available. The gold standard screening tool for CAR is endomyocardial biopsy (EMB), which requires radioscopy and is associated with a $0.2 \%-5.5 \%$ risk of serious complications. Biopsy-negative rejection is a clinically important well-known phenomenon with 10\%-20\% incidence [2].

Several studies have reported that cardiac magnetic resonance (CMR) could detect CAR $[3,4]$. A novel imaging method - dynamic computed tomography perfusion (CTP) — has specificity and sensitivity comparable to CMR. The role of CTP in patients after heart transplantation was described for the first time in our pioneer pilot study [5].

In this case, a 27-year-old woman with end-stage heart failure due to dilated cardiomyopathy underwent OHT on June 2. The donor was a 43-year-old man after head trauma. The cold ischemic time was 170 minutes.

The patient was treated with oral immunosuppression (tacrolimus, mycophenolate mofetil, and prednisolone). An EMB performed on June 12 revealed revealed numerous concentrations of inflammatory infiltrates with the destruction of cardiomyocytes and a Quilty effect (grade 2R). Pulse IV steroids were continued for three days. A second EMB (June 19) showed improvement (grade 1R). A third EMB (June 25) demonstrated recovery (grade $0 \mathrm{R}$ ). However, on the electrocardiogram (ECG), ischemic ST-T changes were observed (Figure 1E). Computed tomography coronary angiography revealed a myocardial bridge in the mid-segment of the left anterior descending artery, and the dynamic CTP showed diffuse irregular areas of hypoperfusion (a "midwall patchy pattern" [MPP]) in the basal and mid segments of the left ventricle (Figure 1A-D) [5]. Myocardial ischemia caused by a myocardial bridge was detected in myocardial segments $13,14,15,16$, and partly in 7. Quantitatively, the myocardial blood flow in the segments classified as normal was $144.9(143.2-147.1) \mathrm{ml} / 100 \mathrm{ml} / \mathrm{min}$, $114.0(109.7-115.0) \mathrm{ml} / 100 \mathrm{ml} / \mathrm{min}$ in the segments with the MPP, and 98.1 (93.2-103.0) $\mathrm{ml} / 100 \mathrm{ml} / \mathrm{min}$ in the ischemic segments. The radiation dose was $2.6 \mathrm{mSv}$. In the fourth EMB, performed after the CTP, grade 1R was found. Considering the low representation of the MPP in the septal segments, it was problematic to prove the ACR grade in the biopsy due to the random localization of the biopsy site.

To conclude, dynamic CTP is a newly developed non-invasive diagnostic method, and its advantages include safety, simplicity, low cost, and that it can be performed in patients with electrodes. As the presented case showed, it is possible to distinguish between ischemic lesions and those associated with 

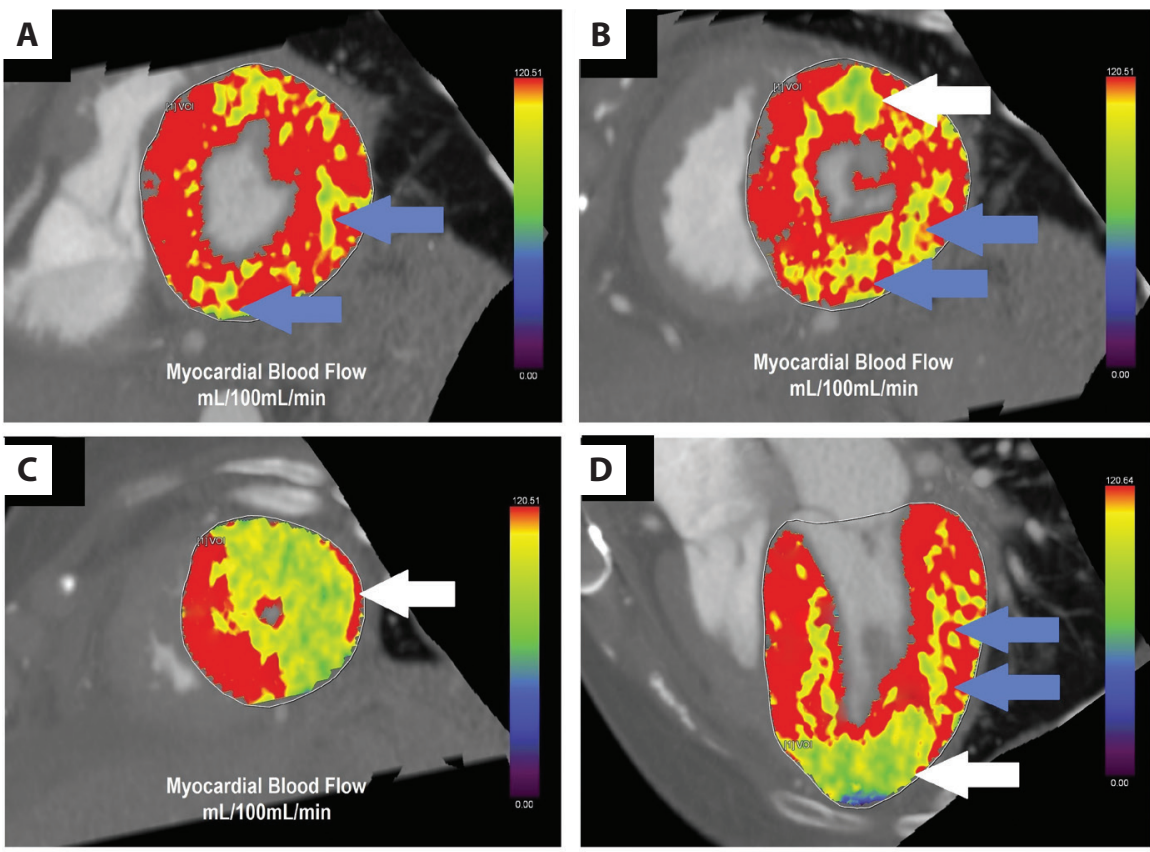

$\mathbf{E}$

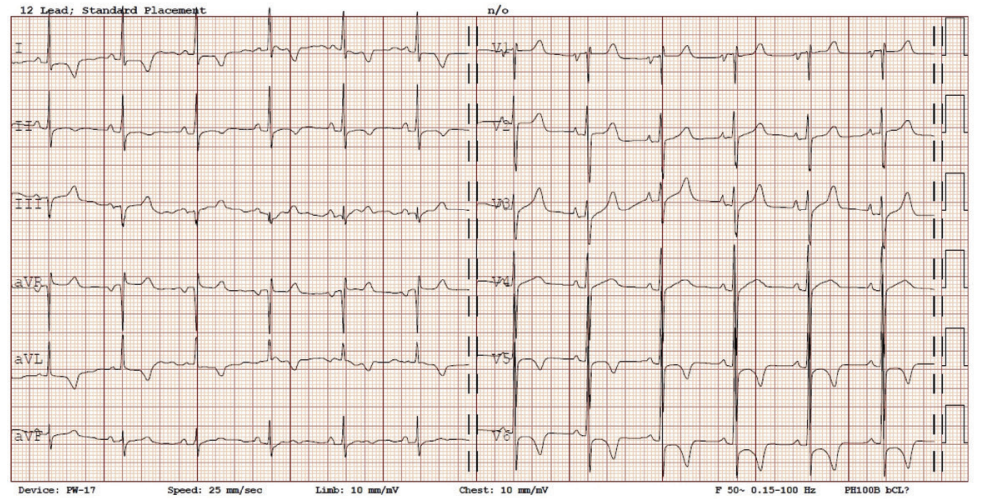

Figure 1. Computed tomography perfusion and electrocardiography. A-D. Dynamic computed tomography perfusion in a 27 -year-old female with early acute cardiac allograft rejection after heart transplantation and a myocardial bridge in the left anterior descending artery. A, B. Midwall patchy pattern in the basal and mid segments of the left ventricle (blue arrows) corresponding to the diffuse inflammatory infiltrates and ischemic pattern (white arrow). C. Typical full-wall ischemic pattern (white arrow) in the apical segments of the left ventricle caused by myocardial bridge. D. Ischemic (white arrow) and rejection changes (blue arrows) in the four-chamber long-axis view. E. Electrocardiogram showing ischemic ST-T changes

rejection in the myocardial tissue in CTP, but these preliminary observations require confirmation in a larger group. The extremely rare presentation of the myocardial bridge in the transplanted heart made this case more interesting because donor's hearts are not tested for this type of anomaly. ECG ischemic ST-T changes after OHT are always suspicious and need further investigation.

\section{Article information}

Acknowledgments: We are very grateful to Professor Maciej Pronicki and the Team of the Department of Pathology at The Children's Memorial Health Institute in Warsaw for EMBs interpretation.

Funding: The study is funded by the Institute of Cardiology — grant number 2.3/V/18 to MSM.

\section{Conflict of interest: None declared.}

Open access: This article is available in open access under Creative Common Attribution-Non-Commercial-No Derivatives 4.0 International (CC BY-NC-ND 4.0) license, allowing to download articles and share them with others as long as they credit the authors and the publisher, but without permission to change them in any way or use them commercially. For commercial use, please contact the journal office at kardiologiapolska@ptkardio.pl.

\section{REFERENCES}

1. Raichlin E, Edwards BS, Kremers WK, et al. Acute cellular rejection and the subsequent development of allograft vasculopathy after cardiac transplantation. J Heart Lung Transplant. 2009; 28(4):320-327, doi: 10.1016/j. healun.2009.01.006, indexed in Pubmed: 19332257.

2. Fishbein MC, Kobashigawa J. Biopsy-negative cardiac transplant rejection: etiology, diagnosis, and therapy. Curr Opin Cardiol. 2004; 19(2): 166-169, doi: 10.1097/00001573-200403000-00018, indexed in Pubmed: 15075746.

3. Imran M, Wang L, McCrohon J, et al. Native T1 mapping in the diagnosis of cardiac allograft rejection. JACC: Cardiovascular Imaging. 2019; 12(8): 1618-1628, doi: 10.1016/j.jcmg.2018.10.027.

4. Dorniak K, Stopczyńska I, van Heeswijk RB, et al. Cardiac magnetic resonance imaging with $\mathrm{T} 2$ mapping for the monitoring of acute heart transplant rejection in patients with problematic endomyocardial biopsy: in anticipation of new recommendations. Kardiol Pol. 2021; 79(3):339-343, doi: 10.33963/KP.15852, indexed in Pubmed: 33687863.

5. Oleksiak A, Sobieszczańska-Małek M, KrukM, et al. Feasibility of computed tomography perfusion for detection of cardiac allograft rejection following heart transplantation. JACC Cardiovasc Imaging. 2020; 13(5): 12861289, doi: 10.1016/j.jcmg.2020.01.004, indexed in Pubmed: 32061561. 